\title{
Frequency of Some Intestinal Parasites of Domestic Fowl Gallus Gallus Domesticus in Djelfa (Algeria)
}

\section{${ }^{1}$ Guerzou Ahlem, ${ }^{2}$ Sahki-Belabbes Ilham, ${ }^{3}$ Milla Amel, ${ }^{1}$ Toumi Khadidja, ${ }^{1}$ Attout Rania, ${ }^{4}$ Doumandji Salaheddine}

${ }^{1}$ Faculty of Nature and Life Sciences, University Ziane Achour Djelfa, P.O. Box, 3117, Djelfa, Algreria

${ }^{2}$ Faculty of Nature and Life Sciences, University Houari Boumediene, Bab Ezzouar, Algeria

${ }^{3}$ National Veterinary High School, El Harrach, 16000, Algiers.

${ }^{4}$ Forestry and Agricultural Zoology Department, National School of Agronomy, El-Harrach, Algeria, Avenue H. Badi El-Harrach

Algiers, 16000, Algeria.

Correspondence Author: Guerzou Ahlem, Faculty of Nature and Life Sciences, University Ziane Achour Djelfa, P.0. Box, 3117, Djelfa, Algreria

Received date: 11 March 2018, Accepted date: 25 May 2018, Online date: 28 May 2018

Copyright: (C) 2018 Guerzou Ahlem, et al. This is an open-access article distributed under the terms of the Creative Commons Attribution License, which permits unrestricted use, distribution, and reproduction in any medium, provided the original author and source are credited.

\begin{abstract}
Domestic fowl parasitism Gallus gallus domesticus is studied in two types of breeding in region of Djelfa by using technical flotation. Following this study, a total of 11 parasitic species is identified. These species are spread on 3 Phylum, 7 classes, 10 orders and 10 families. That test allows us deducing that appearance frequency of parasitic species is in direct relationship with thermal fluctuations. Effect, species of Eimeria sp., Cooperia sp., Ascaridia sp., Toxocara sp., Cestoda sp. ind., Trematoda sp. ind, occur during all sampling's months with a clear predominance of Eimeria sp. Thus, emergence of Nematoda sp. ind. and Strongyloides sp. began only from February and went on until April with low rates for both species. Appearance of Capillaria sp, is present only in February and March and to disappear in April. Their percentages do not exceed $0.5 \%$. The arrival of Syngamus sp. and Isospora sp is observed only in March with low abundance rates for both species.
\end{abstract}

Key words: Intestinal parasitism, domestic fowl, Frequency, flotation, Djelfa, Algeria

\section{INTRODUCTION}

The chicken farming is one of the main activities in pastoral regions. The success of this activity is facing a number of constrains notably hens' mortality in farms sites particularly of traditional type. The main causes of hen's mortality in traditional breeding are particularly infectious and parasitic diseases [3,1]. In Algeria, ongoing works carried out on game parasites, it is worth pointing out those of Idouhar [5] related to farm partridges Alectoris barbara and Alectoris chukka at cynegetic centre level of Zeralda, of Messaoudi and Benabdesselam [6] on turkey parasites Meleagris gallopavo gallopavo and so of Bedrani and Mokaddem [2] on pheasant parasites Phasianus colchicus in Djelfa. As for coprological analyses of domestic fowl, the only works which can be quoted are those of Yousfi [7] in North-West of Algeria, and of Guerzou [4] in region of Sidi Aissa (M'sila, Algeria). The present study is a first test for endoparasite study of the domestic fowl in two breeding types at level of Djelfa region.

\section{MATERIALS AND METHODS}

The present work is carried out in two types of poultry farming located in step region of Djelfa. The first one is a modern breeding achieved in a hangar at 6 $\mathrm{km}$ from Ain El Ibel in Djelfa south region. The second one is a traditional breeding farm located in Bahrara forest where husbandry is limited to familial consumption. It is composed of 20 hens during sampling period. Work in the field is mainly intended to harvest hen droppings from the two breeding sites selected. Droppings are collected of two ways, directly from hen rectum or from the ground with care to collect only droppings freshly excreted by hens. These droppings are preserved in the fridge of the laboratory at $4^{\circ} \mathrm{c}$ in coprology boxes bearing number and date, place of the collection; until their treatment of 24 hours, droppings analysis in made by coprological tests based on flotation method.

Results:

3.1 Global inventory of parasite species of Gallus domesticus found in the two farm sites:

The parasite species number recorded in hen droppings is of 11 species. In the present study, parasites species are spread on 3 Phylum and 7 classes. Species listing of endoparasite identified in hen droppings are classified in table 1.

\subsection{Monthly fluctuations of relative abundance of hen's intestinal parasites species in the two breeding sites:}

Monthly fluctuations of individual's number and species emergences according to monthly average temperatures are highlighted. In January, where lowest temperatures are noted, 6 parasitic species are found Cooperia sp., Ascaridia sp., Toxocara sp., Cestoda sp. ind., Trematoda sp. ind. et Eimeria sp, with high rates for Eimeria. In February, with growth of temperature $\left(\mathrm{T}=8,35 \mathrm{C} .^{\circ}\right)$, the same species are noted but with increase of individuals number of Eimeria sp., Cooperia sp., Ascaridia sp., and Cestoda sp. ind., and population decrease of Toxocara sp., and Trematoda sp. ind, adding these species, three new species are appeared : Nematoda sp. ind. Capillaria sp. et Strongyloides sp. In March, at temperature $10.74 \mathrm{c}^{\circ}$ all species are present with population growth compared to the previous two months and emergence of new species Isospora sp. As for April month, this coincides with the highest temperature average $\left(\mathrm{T}=13,85 \mathrm{C} .{ }^{\circ}\right)$ increase of individuals number of Eimeria sp., Toxocara sp., Cooperia sp., Nematoda sp. ind. and Ascaridia sp, is noted and decrease of population of Strongyloides sp. and Trematoda sp, ind, is observed. Thus during this month, Capillaria sp., Syngamus sp.and Isospora sp. have disappeared (Fig. 1). 
Table 1: Global inventory of parasite species of Gallus domesticus found in the two farm sites.

\begin{tabular}{|c|c|c|c|c|c|}
\hline Family & Species & $\mathrm{I}$ & II & III & IV \\
\hline Nematoda F. ind. & Nematoda sp. ind. & - & + & + & + \\
\hline Cooperiidae & Cooperia sp. & + & + & + & + \\
\hline Ascaridiidae & Ascaridia sp. & + & + & + & + \\
\hline Capillriidae & Capillaria sp. & - & + & + & - \\
\hline Strongyloididae & Strongyloides sp. & - & + & + & + \\
\hline Syngamidae & Syngamus sp. & - & - & + & - \\
\hline Toxocaridae & Toxocara sp. & + & + & + & + \\
\hline Cestoda F. ind. & Cestoda sp. ind. & + & + & + & + \\
\hline Trematoda F. ind. & Trematoda sp. ind. & + & + & + & + \\
\hline \multirow[t]{2}{*}{ Eimeriidae } & Eimeria sp. & + & + & + & + \\
\hline & Isospora sp. & - & - & + & - \\
\hline 10 & 11 & 6 & 9 & 11 & 8 \\
\hline
\end{tabular}

Absence + Presence

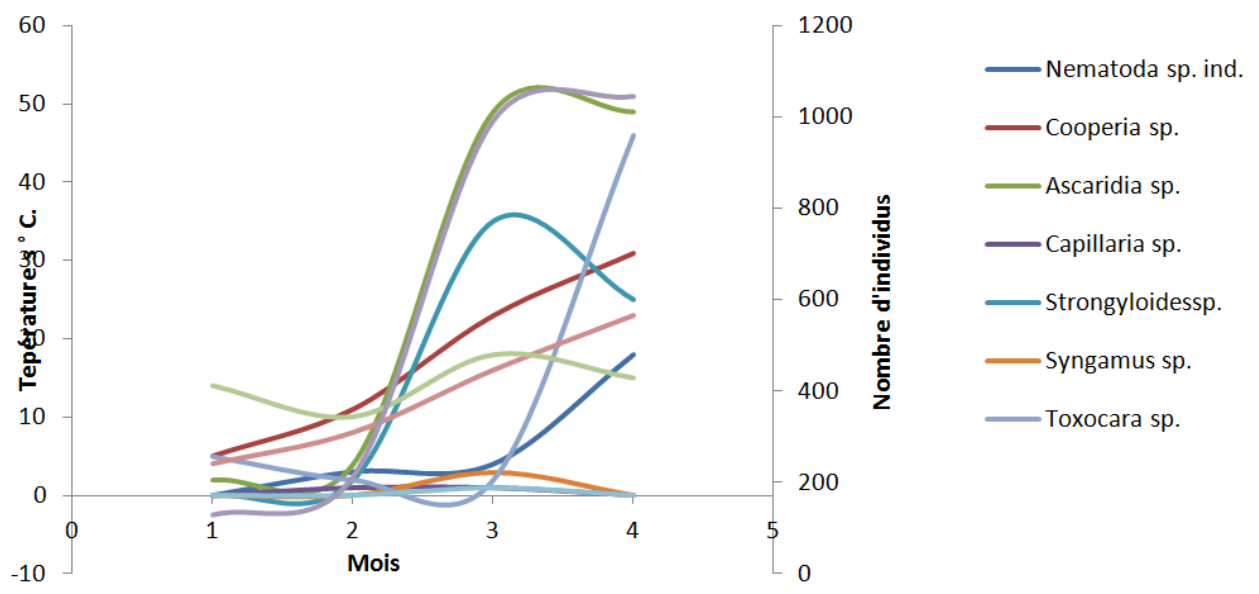

Fig. 1: Monthly fluctuations of relative abundance of hen's intestinal parasites.

\section{REFERENCES}

[1] Ayssiwede, S.B., A. Dieng, M.R.B. Houinato, C.A.A.M. Chrysostome, Y. Issa, J.L. Hornick, A. Missohou, 2013. Elevage des poulets traditionnes1 ou indigènes au Sénégal et en Afrique Subsaharienne: Etat des lieux et contraintes. Ann. Méd. Vét, 157: 103-119.

[2] Bedrani, M.E. B. Mokaddem, 2016. Coprologie parasitaire du Faisan commun Phasianus colchicus (Linnaeus.1758) en élevage à Djelfa. Mém. Master. Univ. Djelfa, pp: 45.

[3] Bonfoh, B., P. Ankers, K. Pfister, L.J. Pangui, B.S. Toguebaye, 1997. Répertoire de quelques contraintesde l'aviculture villageoise en Gambie et propositions de solutions pour son amélioration.Proceedings INFPD workshop, 9 - 13décembreM’bour, Sénégal, 135- 147.

[4] Guerzou, A., I. Sahki-Benabbes, O. Ouahabi, S. Allali and S. Doumandji, 2018. Helminths in the Digestive Tract of Chickens in the Region of Sidi Aissa (Algeria). Recent Advances in Environmental Science from the Euro-Mediterranean and Surrounding Regions, Advances in Science, Technology \& Innovation, https://doi.org/10.1007/978-3-319-70548-4_557.

[5] Idouhar-Saadi, H., A. Smai, M. Aissi, S. Zeni and S. Doumandji, 2012. Eimeria spp. and nematodes infestations in young breeding partridges (Alectoris barbara and Alectoris chukar) in Algeria.

[6] Messaoudi, N., E. Benabdesselam, 2016. Contribution à l'étude des parasites de la Dinde dans la région de Djelfa.Mém. Master. Univ. Djelfa, 77p.

[7] Yousfi, F., Senouci, Medjoual, H. Djelli, T. Hadj Slimane, 2013. Gastrointestinal Helminths in the local chicken Gallus gallus domesticus (Linnaeus, 1758) in traditional breeding of North-Western Algeria. Biodivers J., 4(1): 220-34. 